\title{
Decifrando a cidade: a visão melancólica de Mario Quintana
}

\author{
Anna Faedrich Martins*
}

\begin{abstract}
Resumo: Este trabalho tem por objetivo a análise de elementos como a melancolia, a cidade e a modernidade na obra de Mario Quintana. O enfoque escolhido consiste em observar o sentimento do poeta em relação ao passado irrecuperável e a sua perplexidade face às transformações da cidade, revelando suas inquietações a respeito da temporalidade e do misterioso. $\mathrm{O}$ trabalho visa discutir questões relativas à modernidade, às suas consequiências e à presença da melancolia. Entre os autores consultados para fundamentação, estão Sigmund Freud, Eduardo Lourenço, Susan Sontag, Hugo Friedrich, Walter Benjamin, Sandra Pesavento e Moacyr Scliar.
\end{abstract}

Palavras-chave: cidade; flâneur; melancolia.

\begin{abstract}
The objective of this study is to analyse elements such as melancholy, the city and modernity in Mario Quintana's verse poems. The work focuses on Quintana's feelings about the irrecoverable past and an identification of the poet's perplexity regarding the changes in the urban scenary. It intends to reveal his concerns about time and the mysterious. The methodological approach borrows from Sigmund Freud, Eduardo Lourenço, Susan Sontag, Hugo Friedrich, Walter Benjamin, Sandra Pesavento and Moacyr Scliar.
\end{abstract}

A cidade de Porto Alegre não seria a mesma sem a grande presença do poeta Mario Quintana, que deixou a sua marca na memória emotiva da capital sul-rio-grandense. Ele opta por sair da sua terra natal - Alegrete - ainda jovem, adotando Porto Alegre como a sua cidade, a cidade de seu coração. Todo esse encantamento face à cidade escolhida, todos os seus quintanares de contemplação, faz de Quintana "o poeta da cidade". É o poeta da cidade porque esta é tema recorrente na sua lírica, cidade de múltiplas facetas, capaz de despertar sentimentos diversos no poeta. Mas a cidade vai se transformando ao longo do tempo, se modernizando, enquanto o poeta vai envelhecendo. Ambos trilham juntos os caminhos da vida, numa relação de cumplicidade, com direito a diálogos, idealizações, perplexidade, imaginações, sendo um para o outro a grande companhia.

Mario Quintana é o flâneur que testemunha as mudanças que ocorrem em Porto Alegre, é aquele que caminha e aprecia as suas ruas, as suas casas antigas, as crianças, o

\footnotetext{
* Anna Faedrich Martins é estudante do curso de Letras da UFRGS e pesquisadora voluntária no projeto "A poesia metafísica no Brasil: Percursos e Modulações", coordenado e orientado pela Prof ${ }^{a}$. Dr. Ana Maria Lisboa de Mello, realizado na mesma universidade.
} 
cotidiano. Num momento inesperado, o simples surpreende o flâneur e o inspira a poetizar e registrar aquilo que só ele é capaz de perceber.

Notamos que a temática da modernização, em Quintana, associa-se a sentimentos de perda, de abandono, de solidão e de melancolia. O poeta carrega consigo uma dor nostálgica, mostrando uma certa negatividade face à cidade presente. A visão melancólica de Mario Quintana face à transformação do cenário urbano, o seu descontentamento, fica evidente.

Eduardo Lourenço (1999), em seu livro Mitologia da Saudade, delineia uma leve diferenciação entre os sentimentos de melancolia, tristeza, saudade, tédio e nostalgia. Para Lourenço, a saudade, a tristeza e a nostalgia são sentimentos relacionados à perda de alguma coisa, permitindo, assim, o seu afastamento com a idéia de que se vai recuperar algo. Já a melancolia é mais complexa, pois não tem causa precisa:

Há que lembrar, porém, que a melancolia - porque não é uma modalidade, entre outras, da
sensibilidade e do sentimento, mas uma manifestação estrutural do ser humano, afectado pela
sua relação com o tempo - não pode ser confundida com expressões contigentes da nossa
existência como a tristeza ou a nostalgia. A tristeza e a nostalgia têm causas, origens e
motivações identificáveis na ordem da experiência empírica dos homens. Se bem que se fale
também de "tristeza sem motivo" a propósito de certos estados de alma de ensimesmamento
doloroso. Mas, se acrescentarmos "sem motivo" a essa espécie de tristeza - que se aproxima
assim da melancolia -, é porque para esta paixão há habitualmente uma causa ou um motivo,
real ou suposto. Não é esse o caso da melancolia. (LOURENÇO, 1999, p.100).

Em “Canção de Outono”, percebemos as indagações do poeta Mario Quintana na segunda estrofe - “Tristeza? Encanto? Desejo? / Como é possível sabê-lo?”, uma indefinição própria da melancolia, embora ele utilize a palavra tristeza:

\author{
CANÇÃO DE OUTONO \\ O outono toca realejo \\ No pátio da minha vida. \\ Velha canção, sempre a mesma, \\ Sob a vidraça descida... \\ Tristeza? Encanto? Desejo? \\ Como é possível sabê-lo? \\ Um gozo incerto e dolorido \\ De carícia a contrapelo... \\ Partir, ó alma, que dizes? \\ Colher as horas, em suma... \\ Mas os caminhos do Outono \\ Vão dar em parte nenhuma!
}

(QUINTANA, 2005, p.131)

Freud (1969) aponta para as diferenças entre o luto e a melancolia permitindo-nos um esclarecimento maior sobre essa questão. Ambos estão relacionados à perda de alguma coisa. Freud explica que "o luto, de modo geral, é a reação à perda de um ente querido, à perda de alguma abstração que ocupou o lugar de um ente querido, como o país, a liberdade ou o ideal 
de alguém" (FREUD, 1969, p.275). O luto, após um certo tempo, é superado. Já a melancolia pode ser considerada uma disposição patológica. Na melancolia também existe a reação à perda de um objeto amado, porém é "uma perda de natureza mais ideal", onde "o objeto talvez não tenha realmente morrido, mas tenha sido perdido enquanto objeto de amor" (FREUD, 1969, p.277). Freud observa que o paciente não percebe conscientemente o que perdeu, "ele pode saber quem ele perdeu, mas não o que perdeu nesse alguém" (FREUD, 1969, p.277). A grande diferença do luto para a melancolia é que "no luto nada existe de inconsciente a respeito da perda" (FREUD, 1969, p.278).

Nesse mesmo sentido, Friedrich (1978, p. 31) diz que "melancolia e lamento transformaram-se, afinal, na angústia por aquilo que é inquietante", apontando para a transição do sofrimento com finalidade para o sofrimento sem finalidade, a melancolia sem objeto:

A partir das tendências para a dor dos pré-românticos do século XVIII, estas relações se inverteram. A alegria e a serenidade desapareceram da literatura. A melancolia e a dor cósmica ocuparam o seu lugar. Estes não necessitavam motivo algum para se justificarem, extraíam de si próprios seu alimento e tornaram-se predicados de nobreza da alma. O romântico Chateaubriand descobre a melancolia sem objeto, eleva a "ciência da dor e das angústias" à meta das artes e interpreta a cisão espiritual como bênção do Cristianismo. A consciência de ser decadente propaga-se e é desfrutada como fonte de estímulos insólitos. O destrutivo, mórbido e criminal adquire a categoria de interessante.

Mas apenas no século XIX, quando o sofrimento com uma finalidade passou a sofrimento sem finalidade, à desolação e, por fỉm, ao niilismo, as formas tornaram-se, tão imperiosamente, a salvação - conquanto fechadas em si e repousantes - entrando em dissonância com os conteúdos inquietos. (FRIEDRICH, 1948, p. 30-31, 40).

A modernidade está intimamente ligada à melancolia cujo "eu" é autônomo e múltiplo. Em "Bilhete a Heráclito" percebemos essa idéia dos múltiplos "eus" - advinda do Século XX - onde Quintana diz que não só o rio em que se banha não é mais o mesmo, mas ele também já não é o mesmo.

Tudo deu certo, meu velho Heráclito,
Porque eu sempre consigo
Atravessar esse teu rio
Com o meu eu eternamente outro...

(QUINTANA, 2005, p.513)

Solange Yokozawa (2006, p.233) observa que "a poesia de Quintana sustenta a fragmentação do ser no tempo". Ela aproxima o poeta a Proust dizendo que, para ambos, as etapas vida correspondem a um ser diferente, "eus diversos se sucedem no tempo":

A memória que interessa em Em busca do tempo perdido é a "memória escrita", a memória enquanto motivo romanesco, enquanto tema problematizado ao longo da narrativa. Essa memória já se manifesta quando o leitor se depara com um narrador-protagonista que se põe a recuperar analiticamente os seus "eus" anteriores. No passado recuperado pelo narrador e do qual o leitor toma conhecimento à medida que vai lendo o romance, verifica-se que duas 
constantes, que no fim da obra acabam por se encontrar, assinalam o protagonista: ele alimenta desde criança o desejo de ser escritor e busca entender o motivo de uma felicidade plena que o invade em certas situações. (YOKOZAWA, 2006, p.217)

Moacyr Scliar (2003) faz um estudo sobre a melancolia desde a epidemia da peste negra, por volta de 1347, até a atual depressão dos tempos modernos. O que interessa para o nosso trabalho é a relação que Scliar faz entre a peste negra e a sífilis com a modernidade. Ele associa ambas doenças à melancolia e à modernidade. A peste negra e a sífilis são doenças que ocorrem em movimento de transição, a primeira no fim da Idade Média, e a segunda no Renascimento. O autor observa que a disseminação de ambas foi facilitada pelo contexto histórico - a urbanização, as viagens marítimas — e, no caso da sífilis, pelas guerras e pela maior liberdade sexual. Dessa forma, as doenças "acabaram se associando à transição para a modernidade como uma mensagem sombria" (SCLIAR, 2003, p.34). Scliar aponta também para o surgimento do relógio e, com isso, a nova concepção de tempo e de espaço, mexendo com a cultura do século XIV na Europa: "à medida que as cidades iam crescendo e que a atividade econômica se expandia, surgia a necessidade de novas maneiras de marcar o tempo: mais exatas, mais individualizadas" (SCLIAR, 2003. p.13). Nesta época, assim como o relógio mexeu com a cultura, houve outros adventos que tiveram tamanha importância e posteriores conseqüências como: a alteração do calendário judaico pelo calendário gregoriano, a introdução dos números arábicos, a cartografia, o telescópio etc: "a introdução dos números arábicos, aliás, fez parte do processo de renovação que caracterizou o advento da modernidade" (p.14). O autor aponta para as origens da modernidade, entretanto, para muitos, a modernidade começa com a Revolução Industrial (fim do século XVIII). Desde a sua origem, a modernidade é associada como uma mensagem sombria, e também com um alto custo em relação aos prejuízos que ela trouxe consigo:

Esse progresso não se fez sem um preço. Os Estados modernos surgem em meio a guerras e conflitos. Há riqueza e há miséria; há uma brusca alternância entre o otimismo e pessimismo, entre euforia e desânimo, verdadeira bipolaridade emocional que se traduz em incerteza quanto ao futuro. (SCLIAR, 2003, p.16).

Assim como Scliar aponta para a incerteza do futuro, Eduardo Lourenço (1999) aponta para a idéia de Heidegger sobre a consciência que temos da nossa finitude, essencialmente, "seres-para-a-morte", assim como o mistério da existência que acompanha e perturba a nossa alma. Essa insatisfação com a condição humana, a dor do tempo que foge caracterizar-se-ia a melancolia moderna:

A lírica universal não é mais do que a perpétua tentativa de trazer à superfície a barca afundada dos nossos momentos de eternidade. A poesia antiga conhecia bem a dor inexprimível do tempo que foge, fonte originária da melancolia. Basta lembrar Virgílio ou Ovídio, mas neles o tempo dos deuses e o tempo dos homens era demasiado heterogêneo para fazer nascer na sua 
consciência essa outra dor própria da melancolia moderna de seres insatisfeitos com a sua própria condição humana. (LOURENÇO, 1999, p.98).

Lourenço aproxima os conceitos de melancolia e de nostalgia, reconhecendo "uma profunda afinidade" entre ambos sentimentos, o que dificulta a sua distinção. Ele afirma que a melancolia "não é essencialmente a expressão da nossa derrota como seres simbolicamente imortais", mas sim "a última encenação de todo o nosso ser para aliviar o luto das nossas esperanças desfeitas, dos nossos anseios perdidos, dos nossos amores defuntos" (p.98). Exemplificando isso, Eduardo Lourenço conta a condição de D. Duarte em estar à altura das exigências do pai, que lhe confiara os negócios do estado. Com o sentimento de fazer bem o que acha ser o seu dever, D. Duarte se torna escravo dessa tarefa, abdicando o ócio e os prazeres comuns aos jovens de sua idade. Dessa forma, sente uma real satisfação em cumprir essa tarefa, penitencia-se para isso, porém assalta-o uma tristeza inexplicável - a melancolia -, a incapacidade de compreender o que tem.

Sandra Pesavento (1994) aponta para o fato de que em 1935 a cidade de Porto Alegre passa por um processo de modernização. Porto Alegre está comemorando o centenário da Revolução Farroupilha, vivenciando grandes festas, a Avenida Borges de Medeiros tinha sido inaugurada, assim como o viaduto, as largas avenidas que ligavam o centro aos bairros, a remodelação do campo da Redenção, mudanças inspiradas na matriz francesa, "a cidade exibia para o Brasil e para o mundo o resultado de um longo processo de transformação. A capital do Estado se considerava, finalmente, uma metrópole, atingida pela modernidade" (PESAVENTO, 1994, p.204-205). Contudo, nesta época, embora Porto Alegre tivesse o sonho de ser metrópole, ainda estava em processo tardio de modernização. Na citação abaixo, a autora salienta o desejo de a capital do Rio Grande do Sul alçar-se à condição de metrópole:

Híbrida entre o modelo de Paris e o de Berlim a Porto Alegre do final da década projetava seus
sonhos de ser metrópole no Primeiro Mundo. Era lá o horizonte de chegada de governantes e
das camadas privilegiadas. Uma Paris no Sul talvez fosse o desejo de modernidade mais caro,
mas, entre a cidade ideal e a cidade possível, concretizava-se a ação de engenheiros e
arquitetos alemães que, tanto pela superioridade em termos de concorrência nas limitações
quanto pelo gosto da burguesia nascente de origem teuta, impunha sua marca. (PESAVENTO,
1994, p.205).

Segundo Fischer \& Fischer (2006), embora Porto Alegre estivesse passando por um processo de modernização, a cidade ainda "não conhecia a voracidade e a velocidade das transformações que aconteciam na capital paulista" (FISCHER; FISCHER, 2006, p.24). Os autores comparam o crescimento da população das três cidades, Porto Alegre, São Paulo e Rio de Janeiro. Eles afirmam que "enquanto a capital federal da época, o Rio de Janeiro, era uma cidade grande desde o século 19, alcançando o milhão de habitantes nos anos 1910, São Paulo e Porto Alegre eram, 1880, cidades relativamente acanhadas" (FISCHER; FISCHER, 
2006, p.24-25). Até 1930, "a capital gaúcha manteve um aumento significativo mas lento e por assim dizer harmonioso" (FISCHER; FISCHER, 2006, p.25), diferentemente de São Paulo, onde "a população quase quadruplica entre 1890 e 1900" (FISCHER; FISCHER, 2006, p.25). Os autores apontam para o fato de que embora Porto Alegre ostentasse ares de cidade moderna, devido às mudanças anteriormente já citadas, a capital ainda tinha "um jeitão de cidade pequena" (FISCHER; FISCHER, 2006, p.26).

Quintana registra, na sua obra, as mudanças da cidade de Porto Alegre à medida que vão ocorrendo e mostra a tendência do poeta de ser uma testemunha, como um flâneur, de modernização, que traz consigo inquietude e solidão. Quando o poeta se refere a essa nova cidade, sempre traz consigo a imagem de uma cidade sem pássaros, sem estrelas, sem a tranqüilidade de antes, sem a natureza e a naturalidade de outrora:

\section{ESVAZIAMENTO}

Cidade grande: dias sem pássaros, noites sem estrelas.

(QUINTANA, 2005, p.239)

Em "Eles e as maravilhas", o poeta põe em xeque as "maravilhas" do mundo moderno, feitas de pedra, de aço, metais...:

Eles consideram a Torre Eiffel, a Estátua da Liberdade e o Cristo do Corcovado entre as Sete Maravilhas do Mundo moderno - sem a mínima desconfiança de que poderia ser o contrário.

(QUINTANA, 2005, p.345)

De acordo com Susan Sontag (1987), Walter Benjamin, considerado "un triste" pelos franceses, quando dizia que "a solidão parecia o único estado apropriado ao homem” (p. 87) se referia "à solidão da grande metrópole, a atividade do indivíduo que passeia sem destino livre para sonhar, observar, refletir, viajar" (SONTAG, 1987, p.87). Essa multidão, contraditoriamente, é o lugar do anonimato. E essa é uma das características do ser melancólico "a necessidade de estar só - assim como a amargura da própria solidão"(SONTAG, 1987, p.99). A autora traça o perfil do ser melancólico, dizendo que "o trabalho do melancólico é a imersão, a concentração total" (SONTAG, 1987, p.99).

Segundo Sontag, os melancólicos nascem sob o signo de Saturno - o planeta dos desvios, astro de revolução lenta...:

A influência de Saturno torna as pessoas "apáticas, indecisas, vagarosas", escreve, em A Origem do Drama Barroco Alemão (1928). A lentidão é uma característica do temperamento melancólico. A falta de jeito é outra, e deriva da percepção de um número excessivo de possibilidades, e da não-percepção da própria falta de senso prático. (SONTAG, 1987, p.88). 
Walter Benjamin (1985), em seus estudos sobre a Paris do século XIX e Baudelaire, mostra o poeta como o precursor em tornar a Paris objeto de sua poesia. Não poderíamos falar de Mario Quintana e a sua "pequena cidade grande", Porto Alegre, sem passar pelo estudo de Baudelaire, o primeiro a poetizar a cidade. Ele faz isso através do olhar do flâneur, "o olhar do alegórico a perpassar a cidade é o olhar do estranhamento" (BENJAMIN, 1985, p.39). O flâneur é o detetive da cidade, percorrendo a cidade das transformações urbanas que ocorrem no século XIX, no caso de Paris, a partir das reformas de Haussmann. "A rua se torna moradia para o flâneur, que está tão em casa entre as fachadas das casas quanto o burguês entre as suas quatro paredes" (BENJAMIN, 1985, p.66-67):

\section{DO CADERNO DE UM PERIPATÉTICO}

Melhor sair para a rua... Ou entrar para a rua? Mas se a rua não fosse uma espécie sui generis de lar, por que se diz então "a porta da rua" e não "a porta da casa"?

(QUINTANA, 2005, p.346)

Baudelaire é o poeta da modernidade, até mesmo porque foi ele um dos criadores desta palavra, empregando-a em 1859. O conceito de modernidade para ele é bem diferente dos românticos e é um conceito muito complexo:

Sob o aspecto negativo, significa o mundo das metrópoles sem plantas com sua fealdade, seu asfalto, sua iluminação artificial, suas gargantas de pedra, suas culpas e solidões no bulício dos homens. Significa, além disso, a época da técnica que trabalha com o vapor e a eletricidade e a do progresso. (cf. FRIEDRICH, 1978, p.43).

A modernidade para Baudelaire é dissonante. Ao mesmo tempo em que trata o aspecto negativo, ele faz do mísero, do mau, do decadente, do noturno algo fascinador. Ele é o primeiro a poetizar a cidade, utilizando-a como temática de seu fazer poético. Friedrich (1978) ressalta que Baudelaire é o poeta que vê "a possibilidade da poesia na civilização comercializada e dominada pela técnica", mesclando o banal do cotidiano, do real, com o misterioso. A fantasia é um conceito fundamental na teoria baudelairiana. Ele abre as portas para outros poetas como Rimbaud, Mallarmé, Valéry, na produção poética moderna repleta de obscuridade, absurdo, abismo, magia, abstração, ilogicidade, metalinguagem, ironia, humor, paródia, silêncio, desolação.

O poema "Elegia número onze" mostra a necessidade do poeta - o flâneur - de perderse na multidão. Ele lamenta a falta de gente na cidade deserta. Esse poema retoma a idéia dos versos do poeta moderno Antonio Machado - Caminhante / não há caminhos, / faz-se o caminho ao andar (cf. MACHADO, 1973, p. 158):

ELEGIA NÚMERO ONZE

Não, não é uma série de pontos de exclamação 
- é uma avenida de álamos...

E o que, e para quem, clamariam então?!

Deserta está a cidade.

Todas as avenidas, todas as ruas, todas as estradas, atônitas

se perguntam se vêm ou se vão...

Em nada lhes poderiam servir esses postes de quilometragem:

estão apenas desenhados, como num mapa.

Ah, se houvesse uns passos, ainda que fossem solitários...

Se houvesse alguém andando sozinho... e bastava! São os

- são os passos que fazem os caminhos.

passos

Deserta está a cidade.

Se houvesse alguém andando sozinho

- para ele se acenderiam então, como um olhar, todas

as cores!

Porque a cidade está cega, também.

O que não é visto por ninguém

não sabe a cor do aspecto que tem.

A cidade está cega e parada a descor de um morto.

Porque tudo aquilo que jamais é visto

- não existe...

(QUINTANA, 2005, p.471, Grifo nosso)

O flâneur caminha pela cidade, e é esse caminhar, segundo James Hillman (1993), que está cada vez menos presente na vida do homem moderno. Ele diz que "a locomoção tornouse mecanizada, desde os dispositivos de controle remoto até, claro, os automóveis" (p.51) o que torna cada vez mais desnecessário o caminhar na nossa rotina. A poesia de Quintana consegue perfeitamente retratar o que James Hillman está diagnosticando em 1993. A vida desse novo homem - o homem moderno -, não chama a atenção de Quintana, pois para ele é sem graça viajar de avião e transitar pelos aeroportos. A locomoção com o automóvel, afirma o autor, é uma experiência visual. Já nos aviões, nem a experiência visual acontece:

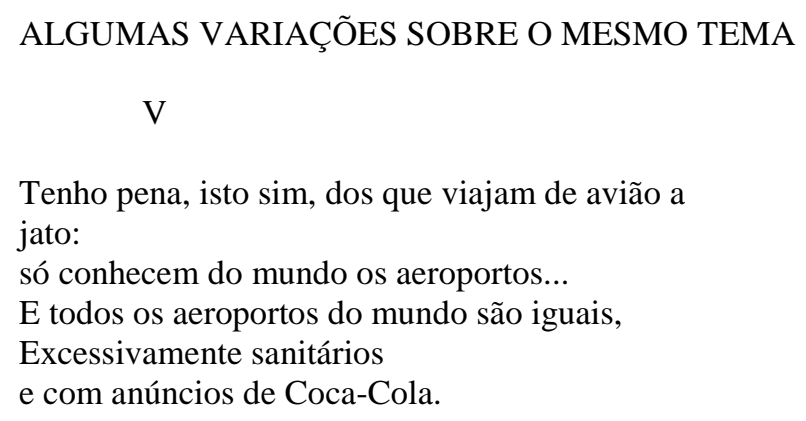

(QUINTANA, 2005, p.417)

Hillman diz que "andar acalma", "caminhando estamos no mundo, encontramo-nos num lugar específico e, ao caminhar nesse espaço, tornamo-lo um lugar, uma moradia ou um território, uma habitação com um nome" (HILMAN, 1993, p.53). O psicólogo Hillman, analista que trabalha com a alma, decide abordar o tema da cidade, pois, mesmo analisando as pessoas num escritório fechado, ele diz que "é precisamente a rua aquilo que adentra o 
consultório" (HILMAN, 1993, p.37). Dessa forma, o seu trabalho se dá com as pessoas da cidade, afirmando que a cidade está na alma delas. Ele aponta para o fato de que a psicologia vem discutindo a questão de a vida urbana ser responsável pelas doenças psíquicas:

No século XVIII, eram as fábricas de gim e a pobreza ou o chocolate e o luxo. No século XIX, era a locomoção veloz das viagens de trem, o ar poluído e a aglomeração de pessoas, pára-sóis e muita leitura - em suma, o que a psiquiatria britânica, em 1867, chamou de "a febril atividade da vida" - que causavam aflição psíquica. Um psiquiatra francês, em 1819, disse: "Cidades de quatrocentas a quinhentas mil pessoas são desvios da natureza". A alma adoece com a tensão urbana. (HILLMAN, 1993, p.37).

É interessante observar que o desejo de "fugere urbem", de escapar da cidade rumo à natureza em prol de uma vida melhor, não se dá apenas no Arcadismo ou nas civilizações atuais. O autor afirma que essa é uma fantasia da humanidade, e uma das favoritas, a idéia de que a alma vive melhor quando diminui o seu ritmo para encontrar o da natureza, afastando-se daquela alma sofisticada e corrompida que é produto da cidade:

O Imperador Amarelo da China, em 2.600 a.C., já lamentava os comportamentos desordenados e excessivos de sua civilização em comparação com aqueles de uma era mais antiga. Hábitos errados de alimentação, sono, sexo e bebida já naquela época, 4.500 anos atrás, na alvorada da história. Claro está que alguma parte da alma humana imagina continuamente uma vida melhor, mais verdadeira "perto da natureza", longe da cidade. Estatisticamente, há um terço (se seguirmos os números do relatório do administrador urbano George Schrader) em cada um de nós que simplesmente quer escapar, um impulso sem base racional. Se devemos culpar alguém pela ruína dos centros das cidades, pela morte no coração da cidade, esse alguém deve ser JeanJacques Rosseau, meu compatriota suíço, que evocou os sentimentos para um retorno à natureza e tirou o nosso coração da cidade. . (HILLMAN, 1993, p.37- 38).

Apesar de essa perspectiva colocar a alma e a cidade em campos opostos, o psicólogo faz, novamente, essa ligação entre a cidade e a alma, mostrando que é possível termos cidades com alma e alma com cidades: "restauramos a alma quando restauramos a cidade em nossos corações individuais, a coragem, a imaginação e o amor que trazemos para a civilização" (HILMAN, 1993, p.38). Em seu ensaio "Cidade \& Alma", ele mostra como e onde a alma existe na cidade: "A alma tem sido sempre associada a uma parte reflexiva em nós ou com a função reflexiva" (HILMAN, 1993, p.38). Dessa forma, a alma existe na reflexão. A reflexão na cidade está constituída "sob forma de piscinas, lagos, galerias, sombras, e venezianas onde ocorrem reflexos" (HILMAN, 1993, p.38). O vidro e o espelho também possibilitam reflexão, porém existe o risco de o sujeito voltar-se somente para a sua superfície, onde a vaidade e a superficialidade vazia somente refletem a si mesmas. Para afastar-se da vaidade e do narcisismo, o vidro espelhado "teria que ser usado para a alma; se quiser tocá-la, ele terá que aprofundar e tornar mais complicado ou complexo o sentido de nossa cidade ao refletir alguma dimensão mais profunda, e não somente deslumbrar-nos” (HILMAN, 1993, p.38).

A segunda imagem de alma é a profundidade. Para Hillman, um dos lugares de profundidade na cidade são as -ainda existentes- ruelas. Porém, elas representam a parte 
obscura da cidade, prontas para o processo de alargamento e iluminação. Ele re-afirma a ligação entre a alma e a cidade apontando para o interiorizar: "enfatizar a interioridade daquilo que está à sua frente ou onde você está. Os significados mais profundos, as complexidades mais profundas de alguma coisa - de forma que, toda vez que você olhá-la ou adentrá-la, ela assume um outro nível de significado” (HILMAN, 1993, p.39).

A memória emotiva é a terceira idéia de alma. A cidade é repleta de memória, de história, de acontecimentos passados e sujeitos históricos que deixaram as suas marcas. Caminhando pela cidade, despertamos a nossa memória emotiva, concretizada através de parques históricos, estátuas de personalidades, memoriais de guerra etc. Mario Quintana e Carlos Drummond de Andrade fazem parte da memória emotiva da cidade de Porto Alegre, foram eternizados em bronze na Praça da Alfândega, no centro da cidade. "A cidade, então, é uma história que se conta para nós à medida que caminhamos por ela" (HILMAN, 1993, p.39). Hillman coloca a cidade, também, como memento mori. Há lugares na cidade que nos lembram a morte, como os cemitérios, os altares, as clínicas, os asilos etc: "Esse lado obscuro da vida humana nos faz lembrar da alma, de maneira que a cidade que fala com a alma e da alma não deixa nada de fora” (HILMAN, 1993, p.40).

A quarta idéia se refere às imagens que encontramos nas cidades. Imagens que orientam - placas, cartazes de rua, grafite -, pois a alma precisa de suas imagens. "A mão humana espontaneamente deixa a sua marca, insistindo em mensagens personalizadas; em todo o lugar a natureza humana imediatamente escreve suas iniciais nos monumentos" (HILMAN, 1993, p.40).

O último ponto destacado é a noção de relações humanas. Hillman (1993, p.42) diz que "uma cidade é construída sobre relações humanas, gente se encontrando, e, entre outras coisas, o amor incrementaria as próprias coisas que são desejáveis numa cidade”. Dessa forma, ele aponta para a importância do olhar. Estabelecemos uma relação através do olhar, quando visitamos uma nova cidade, um novo lugar; precisamos caminhar, olhar, tirar fotos, registrar. Assim como o corpo, o lugar que precisamos para esse corpo, é um lugar de intimidade, "pois a intimidade é crucial para a alma":

Portanto, não é novamente uma questão de divisão entre as duas coisas, trabalho e prazer, cidade e alma, o público diurno e o privado noturno, porque isso tira a alma da cidade. Sempre houve lugares construídos dentro da cidade onde há uma quebra do aparente propósito da cidade. Pensar que o propósito das cidades é econômico ou político é uma idéia, sem dúvida, muito recente. Desde o início, o propósito da construção de uma cidade foi algo instintivo nos seres humanos: querer estar junto, imaginar, falar, fazer e trocar. Precisamos desses assim chamados mercados, lugares onde a quebra pode acontecer: o cafezinho, o pub, os cafés, as cervejarias, a lanchonete, os vestiários, o ringue de patinação, ou mesmo o banco da praça ao sol, onde é possível se fazer uma pausa nos deveres e obrigações do dia. (HILLMAN, 1993, p. 42). 
A modernidade está intimamente ligada à velocidade, dessa forma, o psicólogo James Hillman (1993), adverte em seu ensaio que nós não caminhamos. Médicos têm recomendado aos seus clientes que caminhem, uma vez que correr pode ser prejudicial para alguns. Para Hillman, se é necessária uma prescrição médica para que caminhemos, é porque "estamos vivendo num estranho mundo novo, onde alguma coisa básica foi esquecida" (HILMAN, 1993, p.51). Mas o psicólogo não fala no caminhar como esporte, e sim o caminhar em relação à cidade. Quando caminhamos, fazemos isso de forma tão ligeira, que não observamos a cidade, as ruas servem apenas de acesso aos shoppings, arranha-céus e outros lugares. Andamos pelas ruas e mal sabemos por onde passamos, diante de que casas, ou mesmo por quais pessoas. Há uma multidão ao nosso redor, porém nada enxergamos, é o vazio, o vazio da modernidade...

\section{COISAS DO TEMPO}

Com o tempo, não vamos ficando sozinhos apenas pelos que se foram: vamos ficando sozinhos uns dos outros.

(QUINTANA, 2005, p.237)

\section{Referências}

AUTORES GAÚCHOS. Quintana, poeta. Porto Alegre: IEL, 1988.

ADORNO, Theodor. Lírica e sociedade. In: BENJAMIN, Walter et al. Textos escolhidos. São Paulo: Abril Cultural, 1983. (coleção Os Pensadores)

BECKER, Paulo. Mario Quintana: as faces do feiticeiro. Porto Alegre: Ed. Universidade/UFRGS, EDIPUCRS, 1996.

BENJAMIN, Walter. Paris, capital do século XX. In: KOTHE, Flávio (Org.). Sociologia. São Paulo: Ática, 1985.

FISCHER, Luís Augusto \& FISCHER, Sérgio Luís. Mario Quintana - Uma vida para a poesia. Porto Alegre: WS Editor, 2006.

FRIEDRICH, Hugo. Estrutura da lírica moderna. São Paulo: Duas Cidades, 1978.

LOURENÇO, Eduardo. Mitologia da saudade. Seguido de Portugal como destino. São Paulo: Companhia das Letras, 1999.

MACHADO, Antonio. Poesías completas. 14. ed. Madri - Espasa: Calpe 1973.

PESAVENTO, Sandra. De como os alemães tornaram-se gaúchos pelos caminhos da modernização. In: MAUCH, C; VASCONCELLOS, M. Os alemães no sul do Brasil. Canoas: Ed. ULBRA, 1994. 
QUINTANA, Mario. Mario Quintana: poesia completa. Organização de Tania Franco Carvalhal. Rio de Janeiro: Nova Aguilar, 2005.

SCHÜLER, Donaldo. A poesia no Rio Grande do Sul. Porto Alegre: Mercado Aberto, 1987.

SCLIAR, Moacyr. Saturno nos trópicos: a melancolia européia chega ao Brasil. São Paulo: Companhia das Letras, 2003.

SONTAG, Susan. Sob o Signo de Saturno. Porto Alegre: L\&PM, 1986.

STEEN, Edla Van. Viver \& escrever. Porto Alegre: L\&PM, 1981

TREVISAN, Armindo. Mario Quintana desconhecido. Porto Alegre: BREJO, 2006.

VASSALLO, Márcio. Mario Quintana. São Paulo: Moderna, 2005. (Coleção Mestres da Literatura).

YOKOZAWA, Solange Fiúza Cardoso. A memória lírica de Mario Quintana. Porto Alegre: Editora da UFRGS, 2006. 